\begin{tabular}{|c|c|}
\hline $\begin{array}{l}\text { JAN \&6 1998, } \\
\text { Sta. } 37,20) \text { ENGINEERING DATA TRANSMITTAL }\end{array}$ & 1. EDT 623026 \\
\hline
\end{tabular}

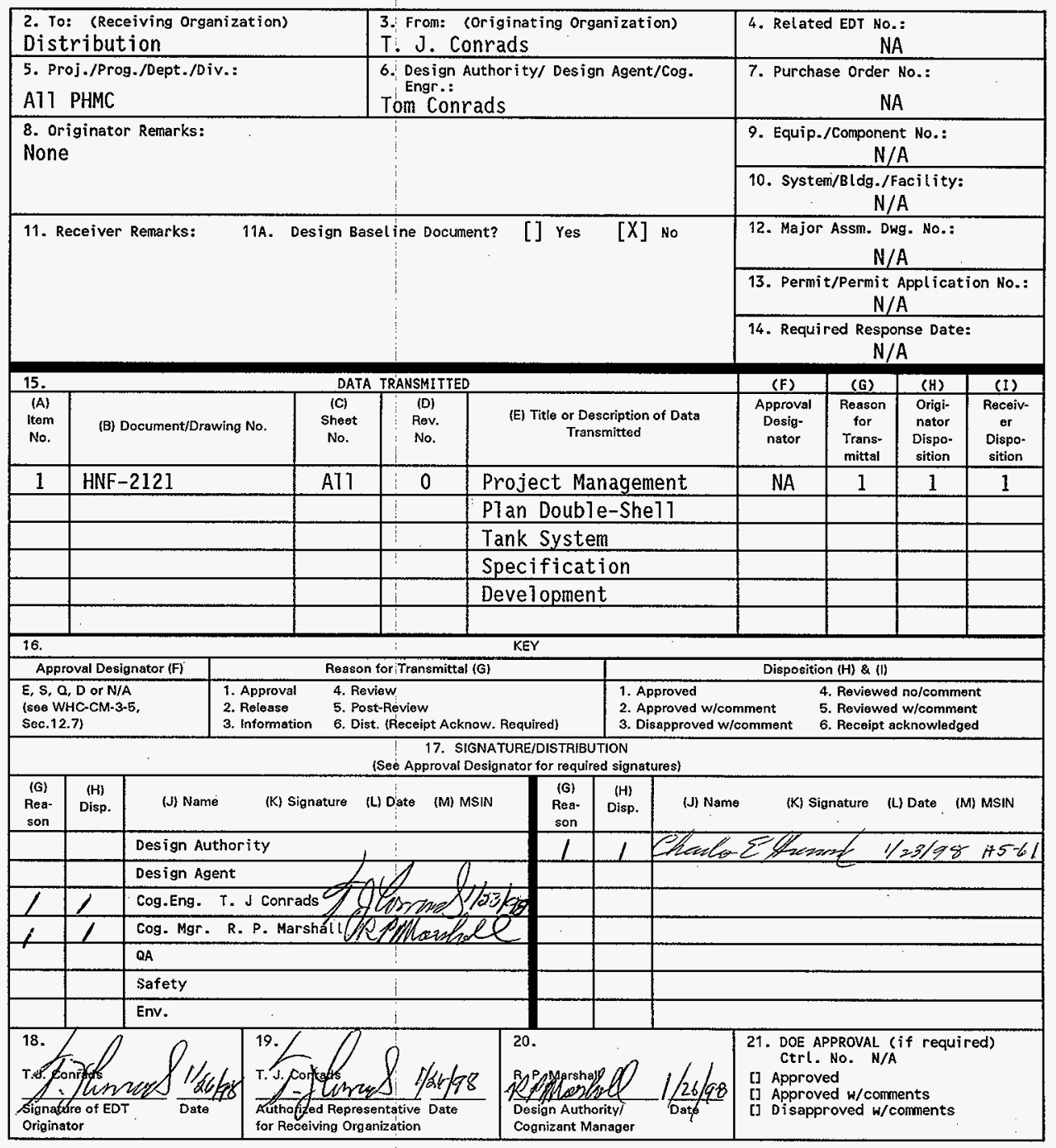

BD-7400-172-2 (05/96) GEF097 


\section{Project Management Plan Double-Shell Tank System Specification Development}

T. J. Conrads

Numatec Hanford Company, Richland, WA 99352

U.S. Department of Energy Contract DE-AC06-96RL13200

EDT/ECN: 623026

Org Code: UC000000

B\&R Code! EW3T30010

Key Words: double-shell tanks, waste retrieval, project requirements, storage tanks.

Abstract: This document describes the process for developing an approach to designing a system for retrieving waste from double-shell tanks. It includes a schedule and cost account for the work breakdown structure task.

TRADEMARK DISCLAIMER. Reference herein to any specific comercial product, process, or service by trade name, trademark, manufacturer, or otherwise, does not necessarily constitute or imply its endorsement, recommendation, or favoring by the United States Government or any agency thereof or its contractors or subcontractors.

Printed in the United States of America. To obtain copies of this document, contact: Document Control Services, P.O. Box 950, Maitstop H6-08, Richland WA 99352, Phone (509) 372-2420; Fax (509) 376-4989.
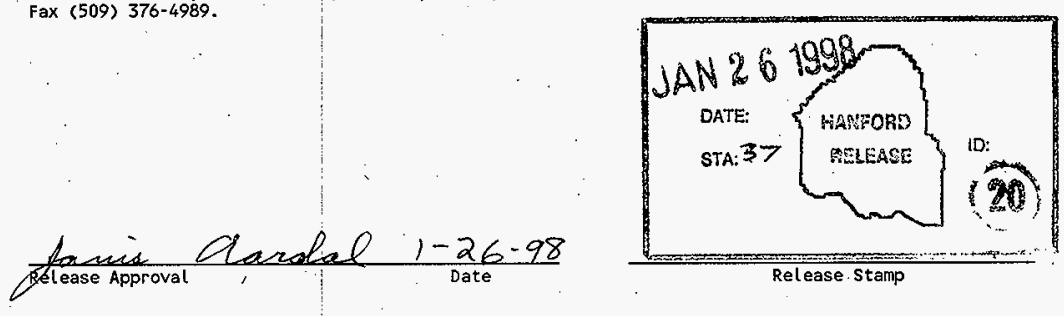

\section{Approved for Public Release}


HNF-2121

Revision 0

\section{Project Hanford Management Contract}

\section{Project Management Plan}

\section{Double-Shell Tank System Specification Development}

Prepared by

T. J. Conrads

NUMATEC HANFORD CORPORATION

November 25, 1997 


\section{NUMATEC HANFORD CORPORATION}

\section{PROJECT MANAGEMENT PLAN}

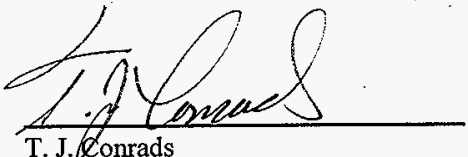

T. J.Conrads

Technical Authority

Numatec Hanford Corporation

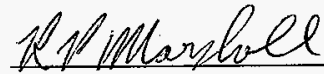

R. P. Marshall

Functional Area Manager

Numatec Hanford Corporation

$$
12 / 5 / 97
$$

Date

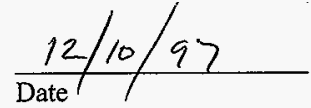


HNF-2121, Rev. 0

\section{TABLE OF CONTENTS}

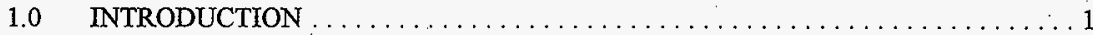

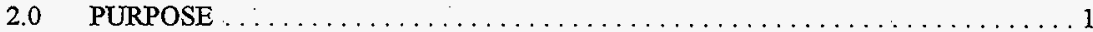

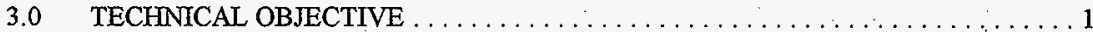

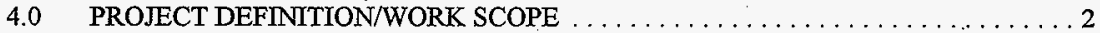

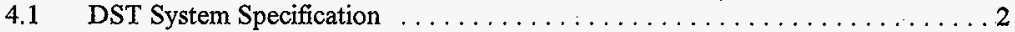

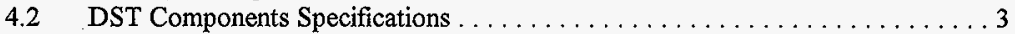

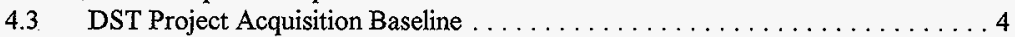

4.4 Configuration Management $\ldots \ldots \ldots \ldots \ldots \ldots \ldots \ldots \ldots \ldots \ldots \ldots \ldots$

4.5 Deliverables ................................. 4

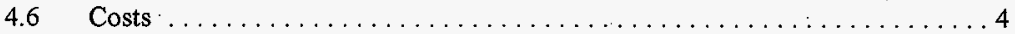

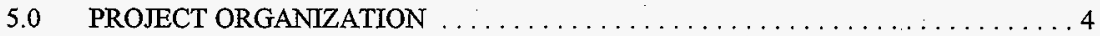

$5.1 \quad$ U.S. Department of Energy, Richland Operations Office . . . . . . . . . 4

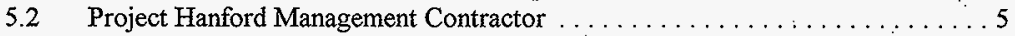

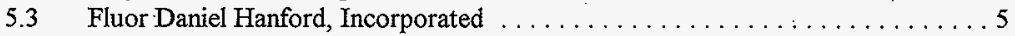

5.4 Lockheed Martin Hanford Corporation/Numatec Hanford Corporation $\ldots \ldots 66$

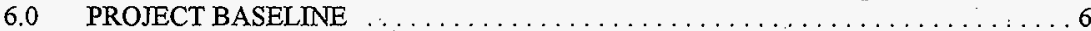

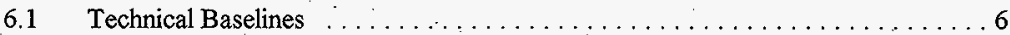

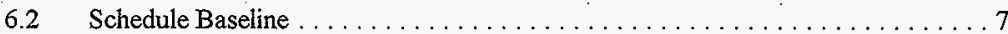

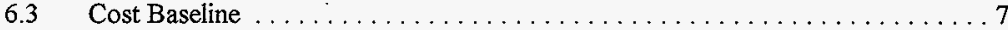

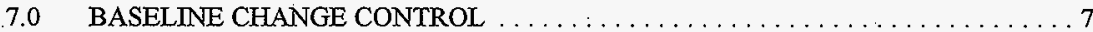

8:0 PERFORMANCE MONITORING AND REPORTING $\ldots \ldots \ldots \ldots \ldots \ldots \ldots 7$

9.0 CONFIGURATION MANAGEMENT $\ldots \ldots \ldots \ldots \ldots \ldots \ldots \ldots \ldots \ldots$

APPENDIX A $\quad$ Project Task Schedule and Notes $\ldots \ldots \ldots \ldots \ldots \ldots \ldots \ldots \ldots \ldots \ldots \ldots \ldots$

APPENDIX B $\quad$ WBS Cost Accounts . . . . . . . . . . . . . . . . . . 
HNF-2121, Rev. 0

This page intentionally left blank. 
EINF-2121, Rev. 0

\subsection{INTRODUCTION}

The Project Hanford Management Contract (PHMC) members have been tasked by the U.S. Department of Energy (DOE) to support removal of wastes from the Hanford Site 200 Area tanks in two phases. The schedule for these phases allows focusing on requirements for the first phase of providing feed to the privatized vitrification plants. The Tank Waste Retrieval Division's near-term goal is to focus on the activities to support Phase $\mathrm{I}$. These include developing an integrated (technical, schedule, and cost) baseline and, with regard to private contractors, establishing interface agreements, constructing infrastructure systems, retrieving and delivering waste feed, and accepting immobilized waste products for interim onsite storage.

\subsection{PURPOSE}

The program described below focuses on developing a systems approach for defining the project requirements for the architecture to retrieve wastes from the double-shell tanks (DST) and designated miscellaneous underground storage tanks (MUST); provide waste feed to privatization contractors for processing and receive by-product from the privatization contractors all in an environmentally sound, safe, secure, and cost-effective manner. This approach uses an integrated requirements-driven, technically defensible physical system configuration that incorporates functional analysis, requirements analysis, alternative generation analysis, evaluation and optimization, and test and evaluation. Specialty engineering, decision/risk management, and interface management are integral parts of the process.

The results of the process will yield definitions of the integrated projects required to support the mission, upgrade the existing architecture where it is lacking, and continue the engineering process to design, construct, and turn over the new or modified facilities. Once the required projects are defined, activities must continue to implement the systems engineering approach and not just focus on the new or modified facilities. Continued implementation of the systems engineering processes, as they relate to the existing architecture, is critical to ensure acceptability of the system as a whole. Test and evaluation and reliability, availability, and maintainability assessments on the existing systems are considered critical elements of this process.

\subsection{TECHNICAL OBJECTIVE}

The technical objective for this project is to use a systems approach to define the integrated project scope to satisfy the mission of waste retrieval, supply feed to the privatization contractors and receive byproduct from the privatization contractors. The scope will address the required modifications to existing systems as well as definition for new structures, systems, and components. 
HNF-2121, Rev. 0

\subsection{PROJECT DEFINITION/WORK SCOPE}

The WORK SCOPE is described in the Tank Waste Remediation System (TWRS) FY-1998 Multi-Year Work Plan and defined in more detail by the Task Schedule shown in Figure A.1 and described in more detail by Task Notes depicted in Table A.1. In general, the WORK SCOPE defines, documents, and maintains the functions and requirements of the DST and system segments supporting the Tank Waste Remediation System (TWRS). It includes completion of planning for resolution of the To Be Determined (TBDs) in the DST System specification, the performance and/or management of selected priority analyses, and preparation of change requests to update the DST System technical baseline. The system level analyses are required to support functional and requirements analyses to get to the component level in support of Phase I DST waste retrieval and feed delivery decisions.

\section{$4.1 \quad$ DST System Specification}

- DST System Specification Support/Performance Analysis:

TWRS defines functional requirements to the 4 th and 5 th levels, and generates the associated performance requirements. (Resolves TBDs in current DST System Specification.)

- DST Project Management:

Conduct management analysis to establish Risk Analysis, and a Schedule Baseline.

- DST Process Analysis

Phase IDST system process parameters will be defined using the Hanford Tank Waste Operations Simulater Software.

- DST Specialty Engineering Studies:

Conduct studies to define Reliability, Availability and Maintainability (RAM), Logistics, Training, and Test and Evaluation requirements based on TWRS management policies.

- Internal Review :

Conduct a review of the DST System Specification limited to the System Specification and its associated planning.

- DST Trade Studies/AGAs:

Trade Studies and AGAs are completed to document engineering analysis and select architectures to support System needs. This scope establishes funding for an Analytical Assessment of the Existing DST System and four small trade/AGA studies. 
HNF-2121, Rev. 0

- DST Interface Control Documents:

This work establishes the interfaces between each subsystem. These documents will provide the basis for delivery and acceptance of products from each subsystem in the TWRS. DST Components Specifications

- DST Component Level Functional Analysis:

Perform additional decomposition of functions, through levels 6 and 7 , as necessary to define DST system. Complete Functional Flow Block Diagrams (FFBD).

- DST Component Level Performance Analysis:

Generates the performance requirements associated with the functions established at the 6 th and 7 th levels.

- DST Trade Studies/AGAs:

Trade Studies and AGAs are completed to document engineering analysis and select appropriate architectures.

- DST Design Component Specifications:

Generate design to specifications for architectures selected by trade studies and Alternative Generation Analysis (AGA). Currently 15 component specifications are expected to be needed including:

\begin{tabular}{ll} 
- & .DST Master I\&C \\
- & Decant Pump \\
- & Slurry/Transfer Pump \\
- & Master Pump Shutdown Controls \\
- & Mixer Pump \\
\hline & Chemical Addition System.
\end{tabular}

4.3 DST Project Acquisition Baseline

This work establishes the requirements and scope for each Project.

Configuration Mánagement

Review and approve changes to the technical and programmatic SST and DST System baselines as needed. Generate and submit updates via change request as lower level Functions and Requirements (F\&R) are developed. 


\subsection{Deliverables}

Major deliverables consist of revised systems engineering documients that define the functions and requirements of the DST System. These documents will support DOE's strategy for facility acquisition. Documents include supporting documents for the DST System Specification, e.g., Trade Studies/AGAs, Interface Control Documents (ICDs) and Component Specifications.

\subsection{Costs}

The estimated costs for this program are $\$ 2 \mathrm{M}$. Funding currently available under TWRS FY-98 Multi-Year Work Plan, project summary work breakdown structure element 1.1.1.3.1.1.3.2 is $\$ 1.62 \mathrm{M}$. Formal change requests will be processed for the difference.

\subsection{PROJECT ORGANIZATION}

The overall responsibility for this project has been delegated by Lockheed Martin Hanford Company to Numatec Hanford Corporation. Major participants in this project are the U.S. Department of Energy, Richland Operations Office (RL), Project Hanford Management Contract (PHMC) Team and other on- and offsite contractors. The PHMC Team is comprised of a number of companies, of which Fluor Daniel Hanford, Incorporated (FDH) is the prime, hereby referred to as the Managing Contractor (MC).

Contractual relations and responsibilities established between $R L$ and the $M C$ are identified in the U.S. Department of Energy Contract DE-AC106-96RL13200. The RL approach for administering this contract is specified in the Contract Administration Plan, Project Hanford Management Contract (CAP). This contract administration style entails partnering with the MC and its subcontractors to achieve mutually beneficial results.

\subsection{U.S. Department of Energy, Richland Operations Office}

The RL Manager (or designee) is responsible for the definition, oversight, and acceptance of the work performed by the PHMC and its subcontractors. The RL Manager has the authority to stop any work activity, add work, and/or withdraw work from the PHMC contract. In addition, the RL Manager has authority for approval of those project Key and Critical Decisions formally delegated to RL by DOE-HQ.

In general terms, the role of RL, with regard to administering the PHMC contract, is to:

- Define success criteria/values

- Establish boundaries for integration

- Set priorities

- Establish strategic performance measures

- Define outcomes/deliverables

- Establish minimum site standards/evaluate results. 
Authority for contractual direction to the $\mathrm{MC}$ is reserved to the $\mathrm{RL}$ Contracting Officer (CO) and designated Contracting Officer Representatives (COR). Overall COR responsibility for the TWRS strategic system is assigned to the Assistant Manager (AM) for TWRS.

The PHMC is a team comprised of 13 companies: a prime contractor/MC, 6 major subcontractors, and 6 "enterprise" companies.

As the MC, FDH has overall responsibility for integrating and directing the work of the other team members. Subcontractor members of the PHMC team include Babcock and Wilcox Hanford Company; Duke Engineering and Services Hanford, Incorporated; DynCorp; Lockheed Martin Hanford Corporation (LMHC); Numatec Hanford Corporation (NHC); and Rust Federal Services of Hanford, Incorporated. The PHMC enterprise companies are B\&W Protec, Incorporated; DE\&S Northwest, Incorporated (DESH); Fluor Daniel Northwest (FDNW); Lockheed Martin Services, Incorporated; Rust Federal Services, Incorporated (RFSH); and SGN Eurisys Services Corporation (SESC).

\subsection{Fluor Daniel Hanford, Incorporated}

As the MC, FDH is responsible and accountable for management of all DST System Specification activities: FDH's role focuses on allocating resources, management, and integration of the work (how and whom), while its subcontractors are responsible for operations (doing the work). The MC role includes defining the work necessary to accomplish the objectives established by RL and working with RL to establish specific Performance Agreements tied to PHMC award fee objectives.

FDH's responsibilities include serving as the prime interface with RL. All contractual requirements and formal communications concerning this project between the PHMC team and RL shall be coordinated through the office of the FDH TWRS Project Director.

The TWRS Project Director is responsible for integrating horizontally across major project boundaries and vertically to DOE and the major subcontractors (e.g., LMHC and NHC). This approach will ensure vertical definition of interfaces and requirements from FDH down through the major subcontractors, and will also provide horizontal integration of interfaces and requirements among major subcontractors.

Programmatic and operational responsibilities for TWRS have been assigned by FDH to LMHC (one of the six major subcontractors in the PHMC team). Direct programmatic ownership of this project is provided by the TWRS Tank Waste Retrieval organization. Within this sponsoring organization, Waste Retrieval Program provides programmatic integration with other projects and provides operations liaison with Tank Farm Operations. 
HNF-2121, Rev. 0

(TFO). Both the Tank Waste Disposal Director and TFO Director report to the TWRS President and General Manager.

Numatec Hanford Corporation provides matrixed project management personnel and expertise to LMHC. The Project Manager, Tom Conrads, who reports to the Waste Retrieval Program manager via the NHC Project implementation manager, Rob Marshall, has direct responsibility and accountability for day-to-day management of this project.

\section{0 . PROJECT BASELINE}

The project integrated baseline is made up of the technical, schedule, and cost baselines. Changes to any of these baselines will require the appropriate revision coordination to the others.

\subsection{Technical Baselines}

The following documents make up the technical baseline for this project:

Grenard, C. E., and Claghorn, R. D., 1997, System Specification for the Double Shell Tank System, HNF-SD-WM-TRD-007, Rev. A Draft, Fluor Daniel Hanford Company, Richland, Washington.

Peck, L. G., 1996, Tank Waste Remediation System, Systems Engineering Management Plan, WHC-SD-WM-SEMP, Rev. 0, Westinghouse Hanford Company, Richland, Washington.

Rieck, R. H., 1996, Tank Waste Remediation System Mission Analysis, WHC-SD-WM-MAR-008, Rev. 1, Westinghouse Hanford Company, Richland, Washington.

Lenseigne, D. L., 1997, Tank Waste Remediation System Fiscal Year 1998 MultiYear Work Plan Work Breakdown Structure 1.1, HNF-SP-1230, Rev. 0, Fluor Daniel Fanford Company, Richland, Washington.

\subsection{Schedule Baseline}

Appendix A includes the baseline schedule for this project.

\subsection{Cost Baseline}

Project Summary Work Breakdown Schedule Element 1.1.1.3.1.1.3.2 reflects the baseline cost for this project. (See Appendix B) 
HNF-2121, Rev. 0

\subsection{BASELINE CHANGE CONTROL}

Changes to baselines are authorized by approval of a change request (CR) in accordance with HNF-PRO-569, Baseline Change Control.

\subsection{PERFORMANCE MONITORING AND REPORTING}

The Project Manager will establish the appropriate monitoring measurements to report progress.

\subsection{CONFIGURATION MANAGEMENT}

Configuration Management will be performed in accordance with HNF-PRO-440. 
HNF-2121, Rev. 0

\section{APPENDIXES}

APPENDIX A Project Task Schedule and Notes

APPENDIX B WBS Cost Accounts 
HNF-2121, Rev. 0

\section{APPENDIX A}

PROJECT TASK SCHEDULE AND NOTES 
HNF-2121, Rev. 0

This page intentionally left blank. 


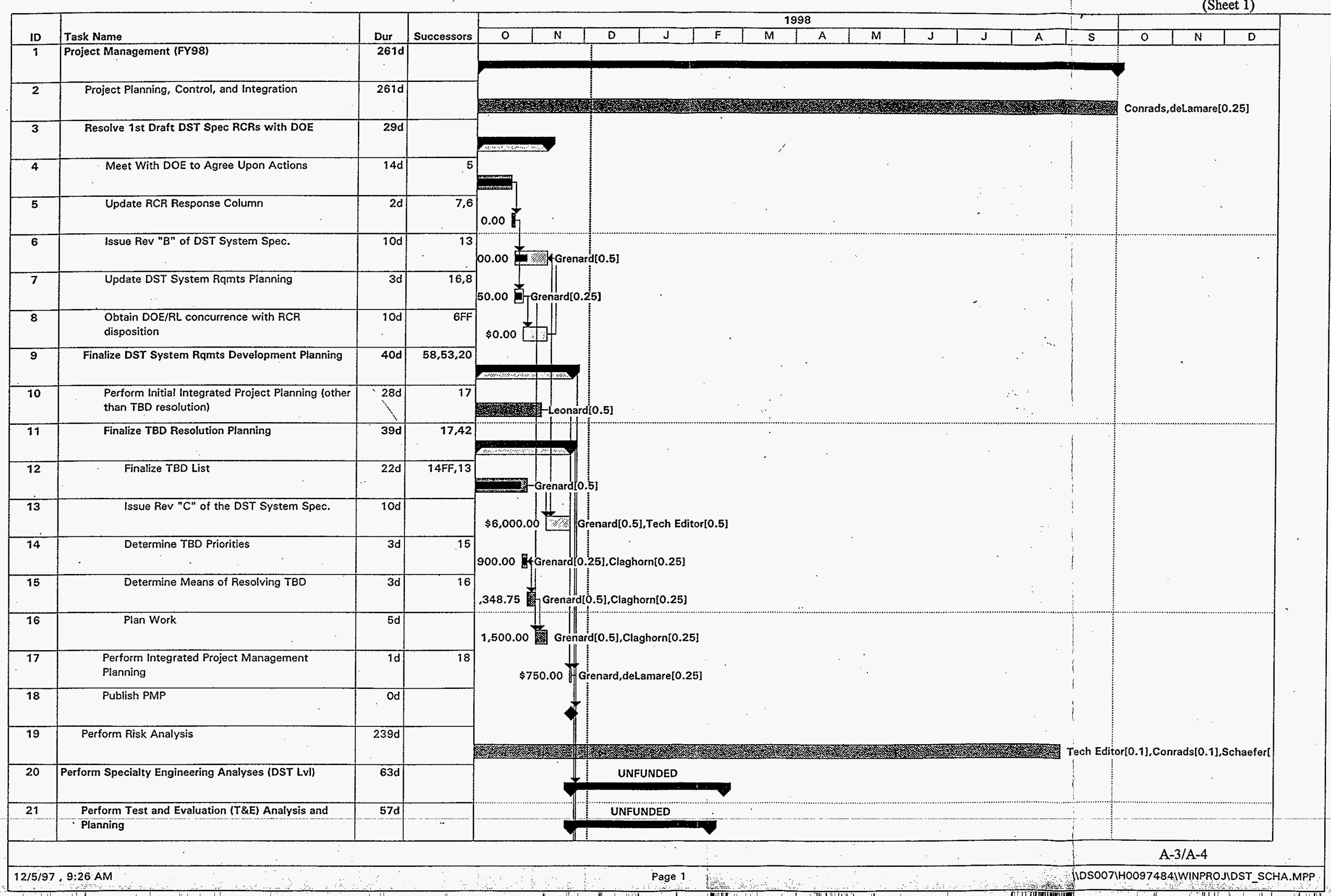




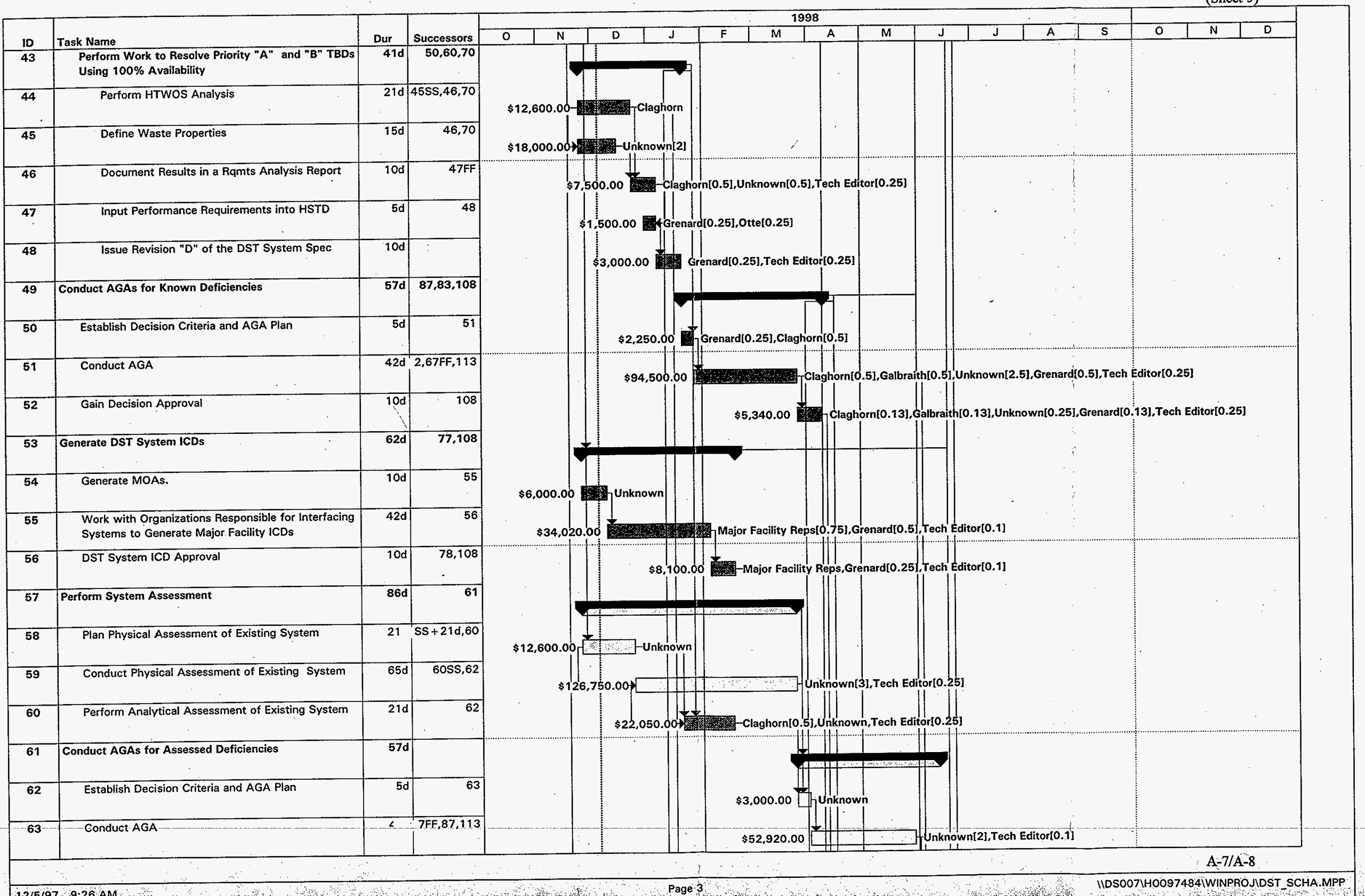

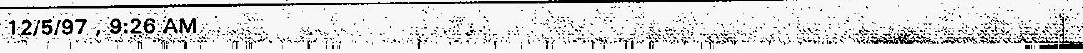




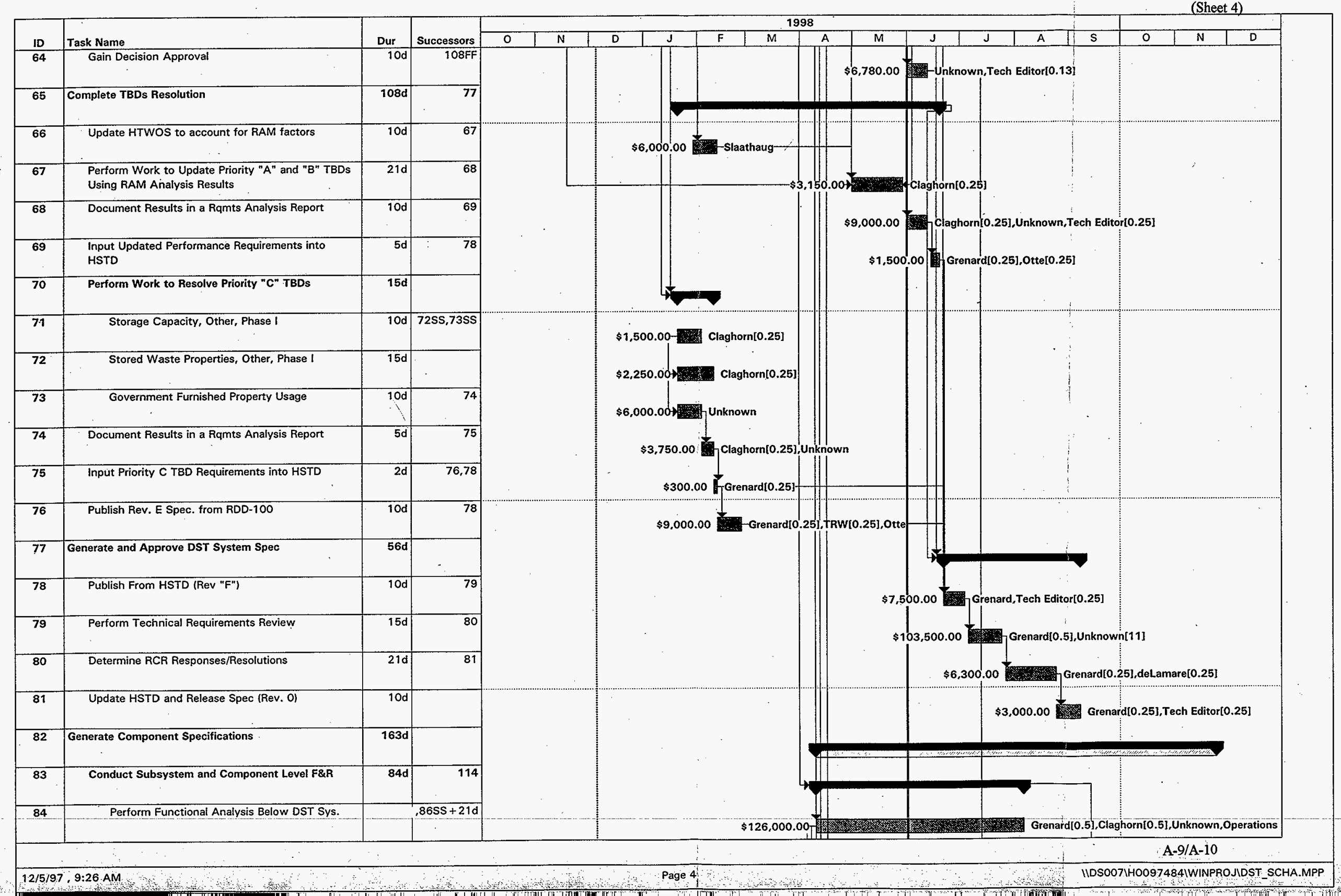




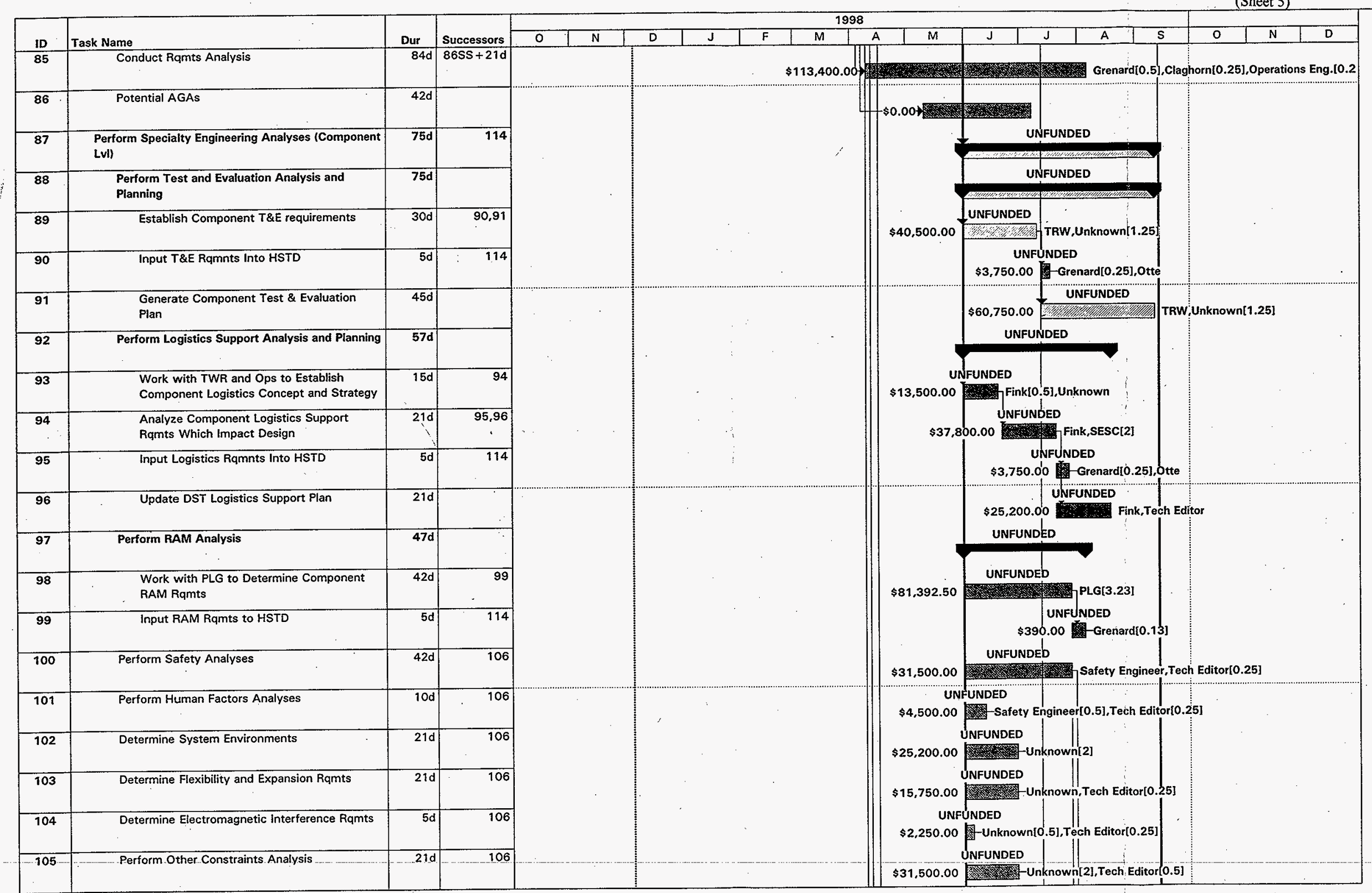




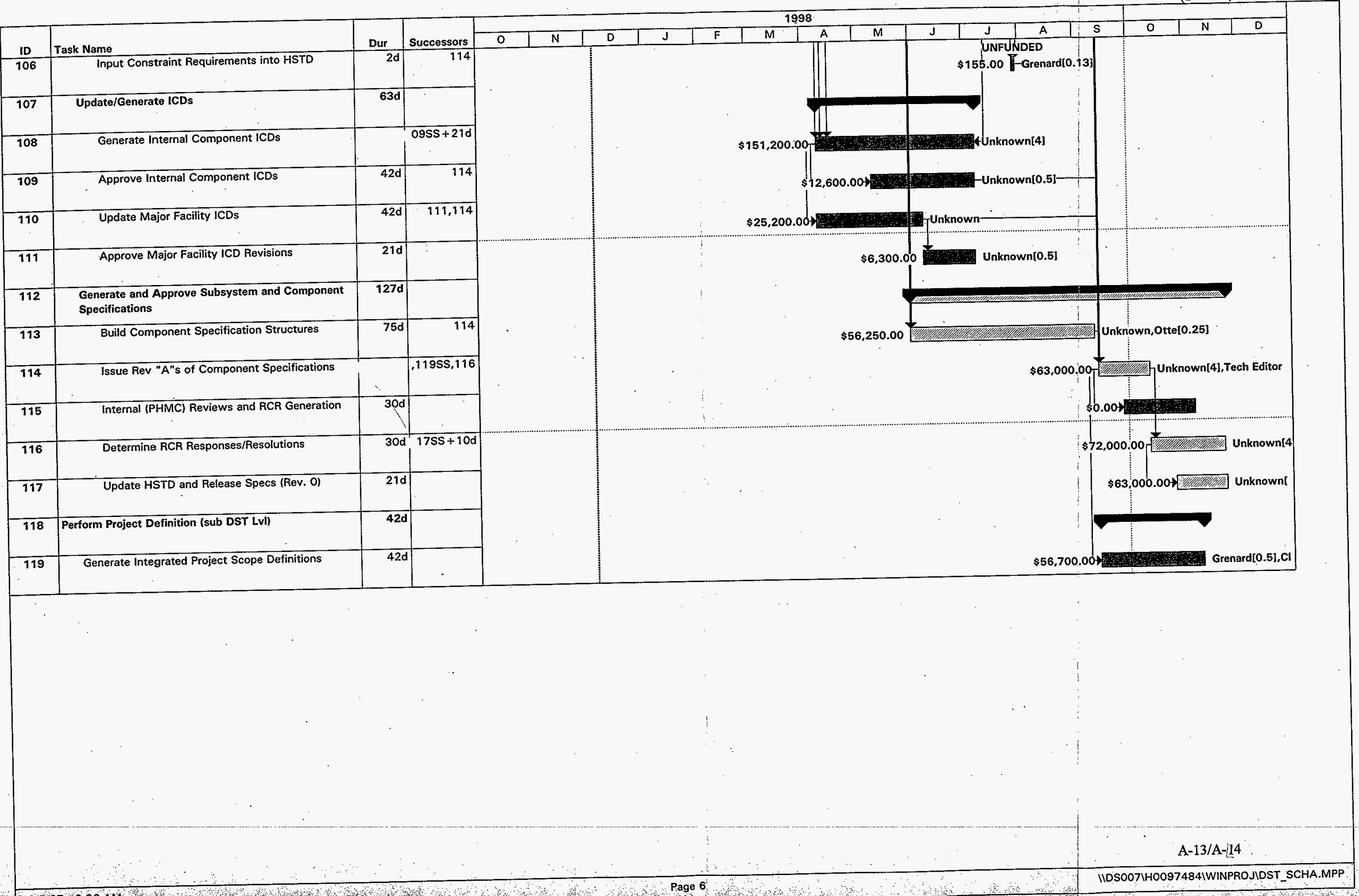


Table A.1. Task Schedule Notes. (Sheet 1)

1 Project Management (FY98)

Rollup of project management activities for FY98

2 Project Planning, Control, and Integration

Generate \& maintain a PMP for Planning and controlling activities. LOE activity for the Project Management. OUTPUT: the management plan (PMP).

3 Resolve ist Draft DST Spec RCRs with DOE

Rollup of activities to resolve DOE RCRs.

4 Meet With DOE to Agree Upon Actions

Reach agreement with DOE on RCR responses. OUTPUT: agreed to review comments records (RCRs) responses.

5 Update RCR Response Column

Update RCR response columns to reflect agreements. OUTPUT: updated review comments records.

6 Issue Rev "B" of DST System Spec.

Provides DOE a spec update incorporating specific changes satisfying "easy" RCR incorporations. OUTPUT: an updated DST System Specification, issued as Revision "B".

$7 \quad$ Update DST System Rqmts Planning

Captures commitments in RCRs and inputs them into PMP. OUTPUT: updated management plan (PMP) with commitments.

8 Obtain DOE/RL concurrence with RCR disposition

This activity presents the DST System Spec RCR dispositions for DOE/RL to concur. OUTPUT: DOE/RL concurrence on review comments records disposition.

9 Finalize DST System Rqmis Development Planning

Rollup of Concentrated activities to generate the initial FY98 PMP.

10 Perform Initial Integrated Project Planning (other than TBD resolution)

Activities to generate the initial PMP (FY98), excluding TBD resolution detailed planning. This activity includes integration of schedule with mid-level logic and RTP scheduling activities. OUTPUT: concurrence with Readiness to Proceed and mid-level logic schedules.

11 Finalize TBD Resolution Planning

Rollup of activities for planning TBD resolution.

12 Finalize TBD List

Scrubs the TBD list now in the specification. OUTPUT: updated Hanford Site Technical Database (HSTD) and generates a TBD list.

13 Issue Rev "C" of the DST System Spec.

Provides DOE a specification update incorporating finalized TBD list and any changes as a result of RCR concurrence. OUTPUT: an updated system specification issued as revision " $\mathrm{C}$ ".

14 Determine TBD Priorities

Prioritizes the TBDs against a predetermined set of criteria. OUTPUT: list of TBDs in priority.

15 Determine Means of Resolving.TBD

Identifies what we must do to resolve each TBD. Some by modeling, other by legwork, etc. OUTPUT: a set of steps to resolve the TBDs.

16 Plan Work

Establishes resources, cost and schedule to resolve TBDs. Also gains commitments from supporting organizations. OUTPUT: an agreed to work plan including resources needed to resolve TBDs.

17 Perform Integrated Project Management Planning

Rolls together activities "Perform Initial Integrated Proj. Planning" through "Plan Work" into single integrated plan. OUTPUT: an integrated project management plan.

18 Publish PMP

A milestone marking the publishing of the PMP. OUTPUT: a published integrated project management plan.

19 Perform Risk Analysis

Qualitative analyzes and manages programmatic risks and integrates them with the TWR risk management program. OUTPUT: a prioritized and approved risk list for DST, Phase I. 
Table A. 1. Task Schedule Notes. (Sheet 2)

Rollup of Specialty Engineering Activities.

21 Perform Test and Evaluation (T\&E) Analysis and Planning

Rollup of Activities to Establish DST System T\&E Requirements and Planning.

22 Establish DST System T\&E Policy \& Requirements

This activity develops DST System design verification requirements and supports TWR. OUTPUT: a supporting document, including guidelines on selecting T\&E methods, and results of application, this is to be placed in section 4 of the system spec. Note: Integration w/ TWRS level data will be reflected when it becomes available.

23 Input T\&E requirements into section 4.0 of the DST Sys Spec

This activity takes the results of activity "Establish DST System T\&E requirements" and inputs the data into the Hanford Site Technical Database (HSTD), using an approved change request, for inclusion in the DST System Spec. OUTPUT: updated HSTD file.

24 Generate a DST Sys T\&E Plan (integrate with TWR)

This activity analyzes how DST System level testing and evaluation will be accomplished. It looks at design verification, acceptance test (ATP), and operational test (OTP) at the system level. OUTPUT: a test and evaluation plan integrated with TWR, to feed the TWRS TEP.

25 Perform Logistics Support Analysis and Planning This is a rollup of activities which establish logistics support requirements.

26 Work with TWR and Ops to Establish a Logistics Concept and Strategy

DST philosophy is to start this activity and aliow TWR to use if they so desire. OUTPUT:A logistics support conceptrstrategy.

27 Analyze DST System Logistics Support Rqmts

This activity analyzes the logistic support requirements for the system by searching other documents. OUTPUT: an acceptable set of DST logistics support requirements.

28 Input Logistics Requirements for DST System Spec into HSTD.

This activity inputs the logistic support requirements for the system into the Hanford Site Technical Database (HSTD) using an approved change request. OUTPUT: an updated set of requirements in the HSTD.

29 Generate an Integrated Logistics Support Plan

This activity generates a logistics support concept. OUTPUT: an integrated logistics support document.

30 Perform RAM Analysis

Rollup of activities for Reliability, Availability, and Maintainability analyses.

31 Work with PLG to Determine DST System RAM Rqmts

This activity works withPLG to determine DST RAM requirements. OUTPUT: a set of reliability, availability, and maintainability requirements.

32 Input Rqmts to HSTD.

This activity takes results from the RAM analysis work and inputs into the Hanford Site Technical Database (HSTD) using an approved change request. OUTPUT: an updated set of requirements in the HSTD.

33 Perform Safety Analyses

Confirm Hazard Class and provide a pointer to the emergency respones to the credible accidents recorded in the bio. Verifies adequacy of requirements in the System Specification section 3.3.6 and 3.3.8 and assigns Hazard classes. OUTPUT: a verified set of safety requirements.

34 Perform Human Factors Analyses

Verifies adequacy of requirements in System Specification section 3.3.7. OUTPUT: a verified set of Human Factors requirements.

35 Identify Natural System Environments

tdentify the appropriate natural environments requirements (e.g. Chemical, Radiation, Vibration, Shock), from existing equiment or work activily. OUTPUT: a set of natural environment requirements, traceable to a supporting document.

36 Determine Induced System Environments

To determine values of induced environments. OUTPUT: a set of induced environment requirements, traceable to a supporting document.

37 Determine Flexibility and Expansion Policy \& Ramts

This activity develops "flexible and expandable" policy not limited to Phase 1, then establishes requirements applicable to the DST system. OUTPUT: a poticy, and a set of requirements for flexibility within Phase 1 and expansion readily expanded to Phase 2. 
Table A.1. Task Schedule Notes. (Sheet 3)

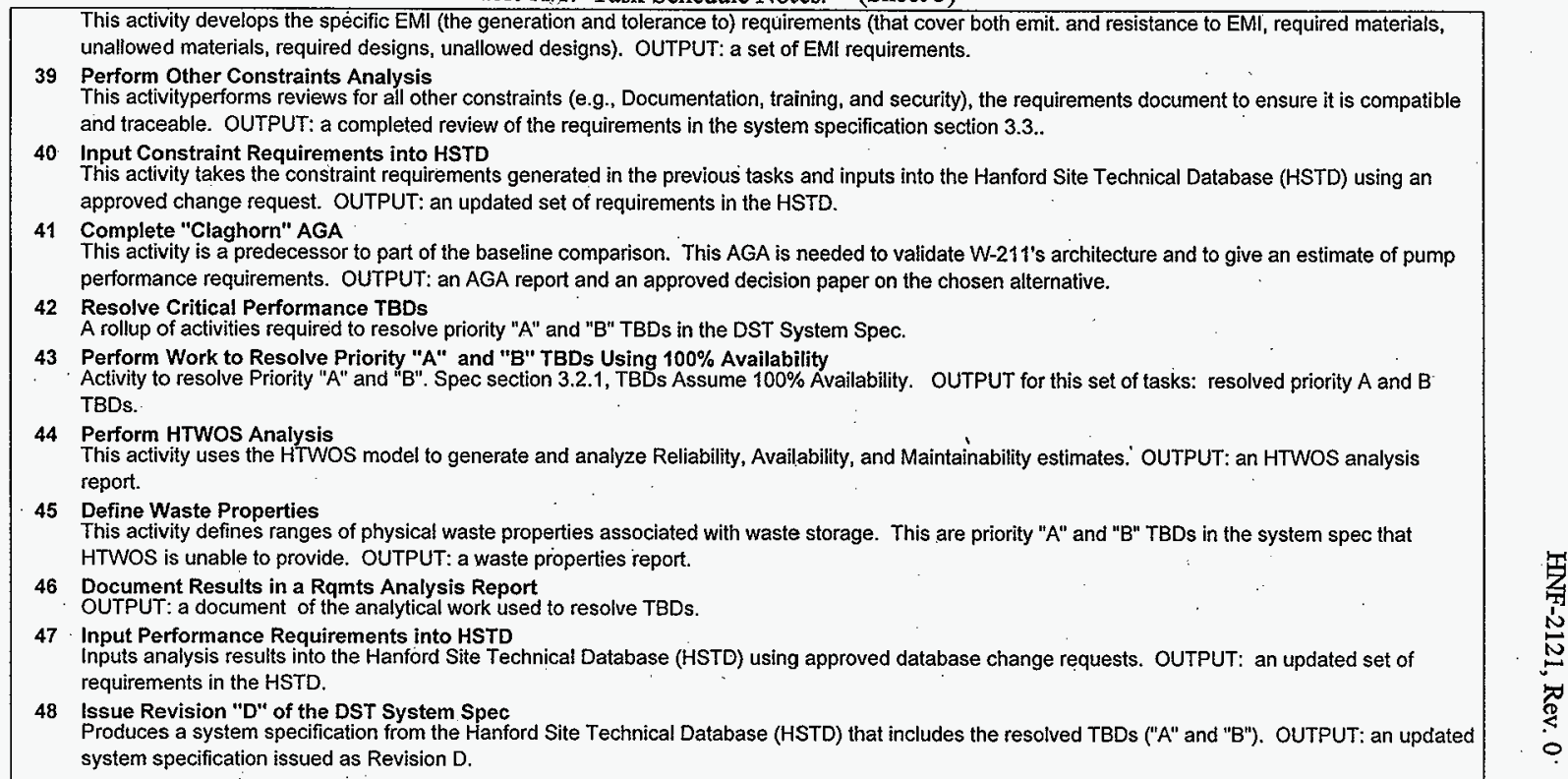

49 Conduct AGAs for Known Deficiencies

Rollup of activities of AGAs for known deficiencies.

50 Establish Decision Criteria and AGA Plan This activity establishes the decision attributes for selecting options for resolving known deficiencies. Know deficiencies include equipment/systems to agitate or mix the waste, to flush the pipeline, to add chemicals, and to agitate or mix of the waste. OUTPUT: an AGA plan and the decision criteria.

51 Conduct $A G A$

This activity conducts the analyses for evaluating component alternatives for known deficiencies. OUTPUT: an AGA report.

52 Gain Decision Approval

This activity presents the information (AGAs) to a decisionmaker for selection of components for resolving known deficiencies. OUTPUT: an approved decision paper with the selected alternative.

53 Generate DST System.ICDs

Rollup of activities to generate ICDs for the DST System Spec.

54 Generate MOAs.

Develop letters documenting the agreements to work interface control between DST System and other Project's Major Facilities (e.g., Waste Management's Central Waste Complex). Agreements include responsibility for developing and maintaining the interface control document (ICD) associated with the DST System interface. OUTPUT: Memorandums of Agreement. 
Table A.1. Task Schedule Notes. (Sheet 4)

This activity identifies all DST system interfaces based on the DST System interfaces captured int the HSTD and based on project personnel interviews. Updates the HSTD after receiving concurrence on ICDs with developers of other major facility specifications (with whom we have MOAS). OUTPUT: Interface Control Documents.

56 DST System ICD Approval Gain signatures to approve ICDs. OUTPUT: an approved set of ICDs

57 Perform System Assessment Rollup of activities for assessing the system, both physically and analytically.

58 Plan Physical Assessment of Existing System

This activity produces a plan to physically assess the existing system capabilities and condition. OUTPUT: an approved plan to assess the existing system.

59 Conduct Physical Assessment of Existing System

This activity implements the physical assessment plan. Visually inspects the physical assets. This task will require the personnel trained to inspect and also the necessary approvals to access the existing equipment. OUTPUT: a report of the physical assessment.

60 Perform Analytical Assessment of Existing System

Perform HTWOS and other analyses of existing system to determine operational capabilities. OUTPUT: an analysis report of the assessment.

61 Conduct AGAs for Assessed Deficiencies

Rollup of activities for Alternative Generation Analyses of assessed deficiencies.

62 Establish Decision Criteria and AGA Plan

This activity establishes the decision attributes for selecting options for assessment deficiencies. OUTPUT: an approved AGA plan and the decsision criteria.

63 Conduct AGA

This activity conducts the analyses for evaluating component alternatives for assessing deficiencies (allows for short-comings). OUTPUT: an AGA report witht the selected alternative.

64 Gain Decision Approval

This activity presents the information (from the AGAs) to the decisionmakers for selection of components for resolving assessed deficiencies. OUTPUT: an approved alternative.

65 Complete TBDs Resolution

Rollup of activities to resolve TBDs.

66 Update HTWOS to account for RAM factors This activity is to update HTWOS to account for RAM factors.

67 . Perform Work to Update Priority "A" and "B" TBDs Using RAM Analysis Results This activity uses HTWOS and other analyses to update TBDs (" $A$ " and "B") using RAM estimates. OUTPUT: an updated list of priority $A$ and $B$ TBDs.

68 Document Results in a Rqmts Analysis Report

Document analytical work used to update TBDs ("A" and "B"). OUTPUT: a Requirments Analysis Report.

69 Input Updated Performance Requirements into HSTD

Inputs analysis results into the Hanford Site Technical Database (HSTD) using an approved change request. OUTPUT: an updated HSTD.

70 Perform Work to Resolve Priority "C" TBDs

This work describes and performs the work to resolve type "C" TBDs. OUTPUT from these tasks: an updated list of priority C TBDs.

71 Storage Capacity, Other, Phase I This activity resolves the storage capacity TBDs in Phase.I. OUTPUT: an update to the staorage capacity TBDs.

72 Stored Waste Properties, Other, Phase I

This activity provides the information (properties) for items such as the Waste Evaporator, that are presently Priority "C" TBDs. OUTPUT: an update to the waste properties TBDs.

73 Government Furnished Property Usage

This activity provides a policy (at system assessment) of what equipment will be used by the contractor that is to be supplied by the Government.

OUTPUT: an approved policy of gov. furnished equip. 
Table A. 1. Task Schedule Notes.

Document analytical work used to resolve TBDs ("C"). OUTPUT: a Requirements Analysis Report.

75 Input Priority C TBD Requirements into HSTD

Inputs analysis results into the Hanford Site Technical Database (HSTD) using an approved change request. OUTPUT: an updated HSTD.

76 Publish Rev. E Spec. from RDD-100

This activity produces the System Specification from the HSTD. OUTPUT: An updated system specification, issued as Revision E.

77 Generate and Approve DST System Spec

Rollup of activities to generate, from HSTD, a Rev E of the system specification (incorporates AGAs, etc.)

78 Publish From HSTD (Rev "F")

This activity produces a System Specification from the HSTD, that has the updates and approval of AGAS. OUTPUT: an updated system specification, issued as Revision E.

79 Perform Technical Requirements Review

This activity consists of a Technical Requirements Review of the DST System Specification and generation of RCRs (comments). OUTPUT: a reviewed system specification and a set of comments.

80 Determine RCR Responses/Resolutions

This activity dispositions comments, provides resolution, and closure of the RCRS: OUTPUT: a set of comment dispositions and responses.

81 Update HSTD and Release Spec (Rev. 0)

This activity produces a specification from the HSTD after the updates are incorporated. OUTPUT: a final draft system specification, issued as Revision 0 .

83 Conduct Subsystem and Component Level F\&R

Rollup of Functions and Requirements activities for the components.

84 Perform Functional Analysis Below DST Sys.

Begin development of planned level 2 specifications. Perform needed Functional, Requirements, Architectural, and Test and Evaluation analyses to develop the required level 2 specifications. OUTPUT: completed functional analyses on components.

85 Conduct Rqmts Analysis

This activity generates preliminary requirements for the component functions needing project level definition; updates the functional analyses to resolve needs identified during the preliminary analyses; and generates requirements for the component functions needing project level definition. OUTPUT: a completed requirements analysis for components.

86 Potential AGAs

This activity provides a placeholder in the event additional AGAs are identified to determine additional components. This may identify additional specifications that need to be generated. OUTPUT: Completed AGAs and Component requirements.

87 Perform Specialty Engineering Analyses (Component Lvl) Component level rollup of numerous analyses in the Specialty Engineering areas.

88 Perform Test and Evaluation Analysis and Planning Rollup of activities for analysis and planning of Test and Evaluation.

89 Establish Component T\&E requirements

This activity develops component design verification requirements and integrates and coordinates component T\&E requirements with the system and operations level. OUTPUT: Component T\&E requirements for section 4 of the Component Specification completed.

90 input T\&E Rqmnts Into HSTD

Inputs the test and evaluation requirements into the HSTD using an approved change request. OUTPUT: an updated HSTD.

91 Generate Component Test \& Evaluation Plan

This activity generates the test and evaluation planning requirements for the environments as coordinated with TWR and Operations. OUTPUT: Component T\&E Plans.

92 Perform Logistics Support Analysis and Planning

Rollup of activities for analysis and planning for component level Logistics Support.

93 Work with TWR and Ops to Establish Component Logistics Concept and Strategy

This activity looks at specific component logistics concepts for components. OUTPUT: Component level logistics concepts reports. 
Table A. 1. Task Schedule Notes. (Sheet 6)

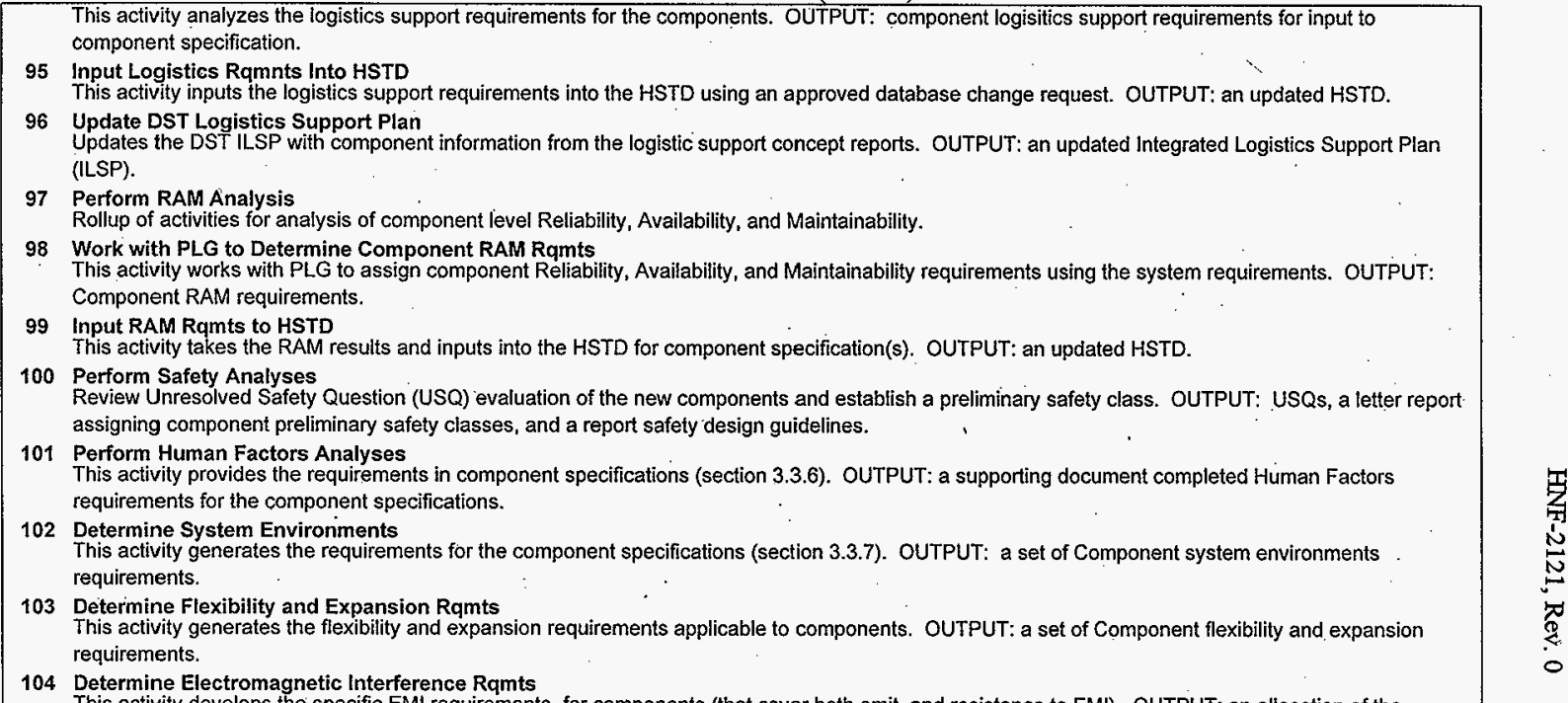

This activity develops the specific EMI requirements for components (that cover both emit. and resistance to EMI). OUTPUT: an aliocation of the Component EMI requirements.

105 Perform Other Constraints Analysis

This activity evaluates constraints identified in DST specification and additional constraint sources for applicability to component in question. In addition, this activity has to convert the constraints to measurable design requirements. OUTPUT: a completed analysis of the constraint requirements.

106 Input Constraint Requirements into HSTD

This activity inputs the constraint requirements into the HSTD using an approved change request. OUTPUT: an updated HSTD.

107 Update/Generate ICDs

Rollup activities for updating and generating DST and component Interface Control Documents.

108 Generate Internal Component ICDs

This activity generates the new ICDs (internal and Major Facility) for Phase 1 components. OUTPUT: a set of Component ICDs.

109 Approve Internal Component ICDs

Gain signatures to approve component ICDs. OUTPUT: approved Component ICDs.

110 Update Major Facility ICDs

This activity updates the major facility ICDs. OUTPUT: updated major facility ICDs.

111 Approve Major Facility ICD Revisions

Gain signatures to approve major facility ICDs. OUTPUT: approved major facility ICD revisions.

112 Generate and Approve Subsystem and Component Specifications

Rollup of activities for component and subsystem specification generation and approval.

$12 / 5 / 97,10: 58 \mathrm{AM}$

IIDSO071H0097484WWINPRONDST_SCHA.MPP

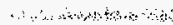




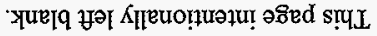


HNF-2121, Rev. 0

APPENDIX B

WBS COST ACCOUNTS 
HNF-2121, Rev. 0

This page intentionally left blank. 
HNF-2121, Rev. 0

\section{COST ACCOUNT}

WBS 1.1.3.1.01.03

\section{TASK\#}

1D2DD30201

1D2DD30202

1D2DD30205*

1D2DD30206

1D2DD30207

1D2DD30208

1D2DD30209*

1D2DD30210

1D2DD30211

ID2DD30212

1D2DD30213

1D2DD302A3

1D2DD302A.8

ID2DD302B3

\section{TASK TITLE}

DST Specification Support

DST System Level Performance Analysis

Technical Requirements Review

DST Component Level Functional Analysis

DST Comment Level Performance Analysis

Trade Studies/AGAs

Design Requirement Documents

DST System Specification

Configuration Management

DST Interface Control Documents

DST Project Acquisition Baseline

DST Risk Analysis

DST Trade Studies/AGAs

DST Life Cycle Cost/Schedule
FY 1998 BUDGET (K)

332.1

74.6

103.7

110.1

53.3

106.5

311.0

70.7

79.6

70.7

29.5

79.6

70.0

120.5

Total

$\$ 1,616.9$

* Note: These tasks have been reprogrammed to support the speciality engineering tasks (Appendix A) at the systems level. 


\section{DISTRIBUTION SHEET}

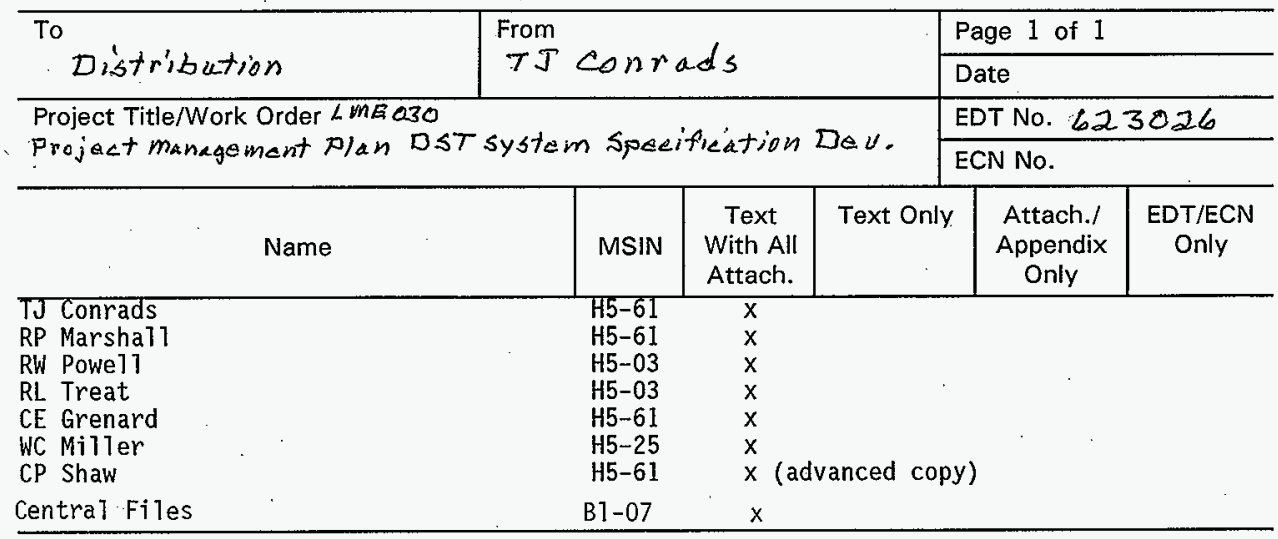

